\title{
A Model of Supermarket Pricing Behaviour
}

\author{
James A. Henry \\ University of Otago, New Zealand \\ John C. Guthrie \\ University of Otago, New Zealand \\ Geri F.H. McLeod \\ University of Otago, New Zealand
}

\begin{abstract}
This research aims to shed light on how prices in supermarkets for consumer items are set. It also explores the changing power relationship within the retail food distribution channels.For this qualitative study supermarket employees and manufacturer employees were interviewed about their perceptions of price setting. The research identified that for Key Value Items (KVI) a number of common characteristics in regards to costing and pricing policies applied to both suppliers and supermarkets. Both supermarket customers and supermarkets competitors also influence these items. While the qualitative method used in this project elicits rich commentary it does expose the project to biased data. The fact that it is country specific could be regarded as a limitation or a starting point for international comparisons. As a consequence of the research it was possible to develop an integrated model of supermarket pricing behaviour. The model follows two streams, one for standard products, and one for KVI, and how they are applied in practice. This model has application to multiproduct organisations where their offering is frequently purchased. The role of the supermarkets in the New Zealand distribution channel has come under scrutiny in recent years. Consumers are demanding knowledge of supermarket pricing practices and are voting with their feet if it is not provided. This paper lifts the lid on pricing behavior to some extent. The research is based on primary research and as such is original. It seeks to build on earlier commentaries on supermarket pricing behavior.
\end{abstract}

Keywords: pricing, supermarkets, channels, FMCG, New Zealand

\section{Introduction}

Issues of pricing are perhaps one of the least understood areas within Marketing. Margins, discounts and profitability are very important for business survival in the long term, but not allbusiness leaders realise that these are often the consequence of pricing policies and practices. The association between supermarkets, the suppliers and manufacturers, in particular, appears to also be poorly understood or misunderstood completely. 
One way to address this is to understand price variation (Ellickson\&Misra 2008). Price variation, or price differentials occurring among different retail outlets for the same branded product, is very common. The astute use of which can enable greater profits for the retailers, in this case, supermarkets.A supermarket in this context refers to retail food outlets that are self-service, are larger than 40,000 square feet and carry at least 30,000 stock keeping units (SKU). Effective understanding of this phenomenon comes with insight into the differing and sometimes competing methods the retailers and the seller (manufacturer/supplier) use to maximise profit. In addition, despite a product being purchased exclusively from a retailer, manufacturers may also be responsible for price variation. Manufacturers predominantly use cost-plus as their method of arriving at a price charged to the supermarkets (Varsanyi, 1986; Gray et.al., 1996).

Channel power indicates the relative strength of the participants (including manufacturers and supermarkets) and their potential actions of both bargaining power and bargaining position (Draganska, Klapper, and Villas-Boas, 2010; Hingley, Lindgreen, and Grant, 2015).Both manufacturers and supermarkets have channel power. Manufacturers' power is provided through consumer demand for their products, thus forcing supermarkets to stock those brands. Supermarkets also possess channel power in New Zealand as they are in a duopoly, and they may exert a major influence on the retail price that consumers pay.

Supermarkets also influence price variation through using price as one of their main promotional tools. Previous research hasindicated that the pricing ofkey value items (KVI) appears to be pivotal to the understanding of supermarket pricing policies. KVI have a distinctive role within a supermarket. That is, these products have distinguishing characteristics including being purchased regularly, are used by a wide range of consumers, have price comparisons made in relation to competitor offerings (Gibson, 1993; Kumar \& Leone 1988; Lal \&Matutes, 1994; Mulhern\& Leone. 1991; Nyströmet. al., 1975; Walters \& McKenzie 1988;Hamilton\&Chernev, 2013). While KVI are likely to be small in number in relation to a supermarket's overall product range, their impact is considered to be important to the overall performance of a supermarket due to the image that they create (Bruce 2010; Kaufmann, Smith \&Ortmeyer, 1994; Mulhern\& Leone, 1991; and Narasimhan, 1988). Alongside the notion of KVI's sits the issue of stock turnover which it relates to (Chun \&Cadeaux 2010).

Very little academic research was found in this area to date, either in New Zealand or overseas. Research in this area is important as retailersappear to have the "upper-hand" in negotiations with suppliers due to the requirement of smaller margins andthe amount of stock sold. Furthermore, supermarkets have been consolidating their brandsand also acquiring other supermarket brands recently, thereby gaining both market share and purchasing power. In addition, supermarket brands have been diversifying into superstores (e.g., The Warehouse, a general merchandise and apparel retailer in New Zealand).

This study will give invaluable insight into pricing practices of the supermarket industry, by exploring the relationship between suppliers and retailers.In this study the relationships explored are between the supplier and the retailer - no middlemen are involved. The aim of this study was to determinewhether it is the supermarket or the supplier that sets product prices that lead to price variation. This study aimed to discover what causes 
price variation and pricing practices, and develop a theory of an integrated pricing approach by the supermarkets.

Two competing ideas were postulated as to why and how this occurs:

1. Supermarkets set prices to consumers by using simplistic methods (e.g. cost plus price). High turnover products attract lower margins within a category. Promotional products within a supermarket category have a lower price because they are given the goods for lower unit price by suppliers.It is expected that supermarket prices will reflect the purchase cost from suppliers and that supermarket overheads will be applied at a constant rate (cost-plus approach- a predominant form of pricing). Furthermore, particular products will have lower margins applied to them to attract volume sales. This would apply to generic products such as biscuits, baked beans and many shampoos.

2. Suppliers to supermarkets set prices by recommending prices to maximise profitability and enhance brand value (for the manufacturer). The mechanism for this is: a predominant cost-plus approach for FMCG, higher turnover products within a product range will have a lower margin applied to them by manufacturers or suppliers, List prices of particular products within a range are modified through negotiation between manufacturers or suppliers and the supermarkets and of manufacturers to determine the extent of private label production and what is their place relative to the normal product range produced.

\section{Methodology}

\section{Respondents}

Prospective respondents were contacted through a variety of industry sources including personal contacts and referrals made by people in the industry. Management from both suppliers and supermarkets from a variety of industries, including dairy products, confectionary, beverages, frozen foods, food processing, and household chemicals, were interviewed.

\section{Supplier interviews}

Thirty-nine face-to-face supplier interviews were conducted. Each respondent was asked open-ended questions regarding level of cost knowledge, application of this costing knowledge, and their knowledge of price setting practices by supermarkets.

\section{Supermarket interviews}

Nine face-to-face interviews with three different supermarket groups were conducted. Each supermarket group interviewed consisted of employees ranging from general managers to buyers. Each respondent was asked how supermarket costs were applied to products purchased from suppliers, how prices charged for products purchased by consumers were calculated, and how variations or modifications in prices charged within the supermarket was explained by the respondent. 


\section{Procedure}

There were four stages of data collection in this study. In-depth interviews of both the suppliers and supermarkets were conducted, followed by a retail audit of commonly purchased items as defined by CPI supermarket products (www.stats.govt.nz). Finally, in-depth interviews were undertaken with manufacturers and suppliers of the products identified in the supermarket audit. Confirmatory in-depth interviews using the same procedure of both the supermarkets and suppliers were conducted later to help validate the data collected.

\section{Coding and analysis}

The data consisted of handwritten/voice recorded responses by the respondents. Two analyses were conducted: manufacturer/supplier employees, and the supermarket employees. All interviews were coded, and the responses were categorised into common themes based on the answers from the respondents. Commonly mentioned categories emerged from the specific statements made by the participants and were recorded on tally-sheets.Responses were grouped onto tally sheets and counted as per occurrence per interview. All of the managers' responses were divided into three areas for analysis, namely product costs, departmental costs, and overheads. Descriptive statistics were calculated for each question, regarding the number and percentage of respondents that had endorsed that theme or method.

\section{Findings}

\section{Supplier interviews}

Suppliers' perceive that supermarkets set prices by either applying a standard category margin only (59\%) or applying a standard margin after adjusting for promotions or discounts $(36 \%)$. Some respondents admitted they did not know how supermarkets set their prices $(5 \%)$.

Suppliers' explanations for why supermarkets adjust standard margins related to making adjustments to match a competitor's action on any particular product. These promotional reasons for altering a product's margin were given by a number of managers, who came from a variety of industries, including dairy products, confectionary, beverages, frozen foods, food processing, and household chemicals. Comments included: "They apply a standard margin, and then adjust it for promotional activities" (S1), and "Margins are lower on promotional lines" (S2). One of the beverage producers said that: "For a promotional product, where the margin was reduced in the supermarket, the supermarket's margin was often supported through a promotional allowance" (S5). One of the household chemical producers believed that the supermarkets did not make good use of margins to maximise their profit. In general, the supplier managers believed that margins were altered unnecessarily, and that well branded items could stand a higher margin than the normal category margin applied by the supermarkets.

One of New Zealand's major food processors monitors the retail prices of its products and stated that "While standard margins are applied, particular sizes are discounted" (S18). Within the dairy industry, particular sizes with high volumes had reduced 
margins, and these were often the products that were subject to contract price negotiation. Ingredient producers also believed that supermarkets applied a common margin, except for the higher volume selling stock units (SKU) that had lower margins applied to them.

\section{Supermarket interviews}

All of the managers stated that all individual product costs were fully known, and were kept up to date on a weekly basis. Direct departmental cost data was described as being the furthest extent to which accurate cost data was known. However,a former general Manager believed that a supermarket's knowledge of costs was not as complete as it could be. Even within a department, not all costs are known, and as one manager said: "We don't have specific figures for areas like freezers" (S2). Costs that were recovered from manufacturers or suppliers in the areas of stocking, display material, or product support were not taken into account in the calculation of departmental costs or profitability.

From the discussions held with the supermarket industry,it was demonstrated that they have very accurate and timely cost data on the packaged goods that they purchase for resale. They do not, however, have a high level of sophisticated information regarding non-product costs in relation to the packaged goods section of the supermarket at the present time.

The managers were asked about what knowledge they had of cost data. They were asked how overhead and other non-direct product costs were allocated to any particular product. Supermarket managers' knowledge of non-direct product cost allocations, the majority (89\%) believed that category margins allow for overheads and desired profit, while $11 \%$ stated that departmental overhead was added as a percentage to each category.

Responses regarding price variation by supermarket respondents were divided into manufacturer or supplier conditions and the supermarket's own direct action after the products were purchased. The savings on pack sizes mentioned by one of the ownermanagers related not to an individual pack on the shelf, but to the volume of consignments of a pack size purchased from a supplier. This could range from several cartons of product up to a pallet. Savings due to this are similar to the volume discounts that were mentioned by another area manager. Both of the buyers stated that they were aware that the unit prices did vary, and that this was due to contract prices being established for a particular size such as the two-litre milk bottle. Table 1 shows supermarket managers' explanations for price variation.

Supermarkets themselves can also play a role in reducing the price of particular products, and this was seen to be the case by all managers. The most common explanation, used by all but one interviewee, was the effects of a promotion. The effect of this was often a reduced margin and this, as a former general manager pointed out, was often applied to items that are frequently purchased like baked beans. The reduction in margin was seen by two managers as a way of enticing custom, and was a normal activity for a supermarket. One of the owner operators offered a dual explanation: some promotional lines had either a lower cost or a lower margin and that this was designed to build turnover within a store. 
Table 1: Supermarket Managers' Explanation of Price Variation

\begin{tabular}{|l|c|c|}
\hline Price modification type & $\#$ & \% \\
\hline Manufacturer or supplier set & 16 & 32 \\
Bulk /volume order discount & 13 & 26 \\
Customer category discount & 1 & 2 \\
Standard discount structure & 6 & 12 \\
Allowance/incentive paid & 3 & 6 \\
Promotional discount & 1 & 2 \\
Market price & & \\
Supermarket influenced & 6 & 12 \\
Negotiated price & 4 & 8 \\
Contract price & & \\
\hline
\end{tabular}

Supermarket respondents reported that they had either negotiated the price or had contract prices in place for $20 \%$ of the total range of price modifiers. These prices related to a particular product size within a brand range such as the $1 \mathrm{~kg}$ block of cheese and the 2lt container of milk. They did not relate to the full brand range of any of the products within the survey where managerial staff where interviewed. The effect of this practice was to lower the price for that product and to create the potential for a price variance within a brand range.

\section{Supermarket management knowledge of how retail prices are set}

To establish how supermarkets set their prices, and to confirm what manufacturers and suppliers thought happened, the supermarket managers were asked what knowledge they had of how they set the price of the products supplied to them. Table 2 summarises the opinions held by those interviewed from within the New Zealand supermarket industry.

According to all of the respondents, price setting in the supermarket industry could be characterised as being one of cost-plus. Each organisation has defined and grouped products into particular category groups, such as packaged groceries, bakery, fresh meat, wine, and fruit and vegetables etc. Each of these categories is given a set margin. Because most of the products contained in this survey belong to the single category of packaged grocery products the margins applied will be consistent. As the category margins do not vary within a product range, any unit price variation could be directly related to the manufacturer or supplier prices.

The managers of the supermarkets also expressed the view that most products carried a category margin. The most common method of setting a retail price was cost-plus. However, the managers indicated that some differences in margins did occur. Supermarket managers were aware that prices were adjusted within the supermarkets and they gave the following explanations for their application. The adjustment of list prices in categories where higher turnover attracted a lower margin occurred in $36 \%$ of cases. One product that was mentioned as carrying a lower margin for this reason was two-litre bottle of milk. Price adjustments as a reaction to competitive actions occurred in $18 \%$ of cases. Consumer demand characteristics for such items as fresh fruit and bakery products was also cited as a reason for altering margins in $18 \%$ of cases. 
Table 2: Supermarket managers view of supermarket price-setting practices

\begin{tabular}{l|c|c}
\hline How supermarkets set prices & $\#$ & $\%$ \\
\hline Cost plus category margin & 7 & 78 \\
Cost plus a standard margin & 2 & 22 \\
\hline
\end{tabular}

\section{Manufacturer or supplier price modifiers}

Manufacturers or suppliers use a variety of methods that effectively reduce the price of a product. If the method used is based upon a single product, as opposed to a brand range then it has the potential to vary the unit price. Table 3 explains how organisations might modify their prices to supermarkets.

Table 3: Manufacturer/supplier views of the influence of product turnover on manufacturer or supplier margins

\begin{tabular}{l|c|c}
\hline Influence of turnover on margin & $\#$ & $\%$ \\
\hline High turnover products = lower margin & 17 & 44 \\
Taken into account & 4 & 10 \\
Low turnover products - higher margins & 2 & 5 \\
High volume products attract price pressure & 2 & 5 \\
Differing ranges have differing margins & 1 & 2.5 \\
Not directly taken into account & 13 & 33 \\
\hline
\end{tabular}

When questioned how list prices were modified, $18 \%$ of the responses from manufacturers indicated that they applied either a promotional discount, paid an allowance or provided some form of monetary incentive. Where promotional discounts were applied by the suppliers to the supermarkets, their application was limited to a single product and for a limited period of time. The effect on any price variation was therefore of limited duration. Allowances and incentives related to a product or range of products but they were not applied to a product's individual price. They are either paid as lump sum to a supermarket, or given as a credit to a supermarket's account. As such they have no actual effect on any unit price variance.

In $60 \%$ of cases manufacturers and suppliers used some form of discount structure, which included bulk and volume order discounts, a standard discount structure based on a variety of criteria or a customer category discount. Bulk order or volume discounts were applied in $32 \%$ of all cases, and were applied to a specific product size within a brand range. The standing discount structure was applied across an entire brand size range. Customer category discounts were applied in $26 \%$ of all cases. The basis for the application of these was the type of buyer, such as supermarket, wholesaler etc. The discount was a single tier design, and was applied to all products offered by that manufacturer or supplier. Therefore, where discounts are applied for bulk or volume orders, then there is a potential for unit price variation. Where prices are obtained through either contract or negotiation, then it is likely that there will be a variation in the unit price.

\section{The influence of product turnover on manufacturer or supplier margins}

Manufacturers and suppliers did reduce margins in a variety of ways. As a check to establish whether these were done as part of a trade-off between volumes sold and margins achieved, the managers were asked directly about the influence a product's 
turnover had on the margin that was applied to it. The results of this question are reported in Table IIIwhich shows the influence of product turnover on manufacturer or supplier margins; $33 \%$ of the managers interviewed reported that turnover was not taken into account when setting a product's margin. Further analysis of this group reveals that they apply a variety of discounts, including bulk purchase and, in some cases, contract or negotiated prices for particular products. All of these actions may affect the unit price of a particular product size offering.

When the 'high turnover low margin' category is combined with the 'low volume higher margin' category and the 'taken into account' category, they represent 59\% of interviewees who took volume into account when setting a margin. Thus manufacturers' price setting policies are likely to have an impact on the unit price of any particular product size. This result would indicate that if a product has a lower margin applied to it then it has potential to also have a lower price. Those items that are represented by high volume and low margins (frequently purchased by consumers) are referred to as key value items (KVI).

\section{A summary of results}

1)A cost plus approach to pricing is predominant among manufacturers or suppliers of FMCG products. 2) Higher turnover products within a product range will have a lower margin applied to them by manufacturers or suppliers. 3) List prices of particular products within a range are modified through negotiation between manufacturers or suppliers and the supermarkets. 4) An investigation of manufacturers to determine the extent of private label production and what is their place relative to the normal product range produced. 5) The most often applied method of pricing in supermarkets is cost plus. 6) High turnover products attract lower margins within a supermarket. 7) Promotional products within a supermarket have a lower unit price.

\section{Discussion}

\section{Overview of results}

This study gives invaluable insights into pricing practices of the supermarket industry, by showing the link between suppliers and retailers. The research conducted also explores the potential cause of unit price variation investigated the pricing practices and policies of both the supermarkets and the suppliers and manufacturers to the New Zealand supermarket industry.

The results reveal two basic types of price setting practice that can, for the first time, be described and illustrated. The first type involves the price setting practice of supermarkets where standard category margins are applied to products purchased from suppliers or manufacturers. The second type involves the price setting practices of the supermarkets where Key Value Items (KVI) are involved.

The results show that supermarkets, rather than suppliers, have a major influence on retail price that consumers pay. Supplier and supermarkets management indicated that are constantly reviewed and negotiated to drive down supplier pricing. 
This research then drew upon interviews with managers from all New Zealand supermarket chains, the price audit of a New Zealand supermarket basket of packaged products, and content analyses of supermarkets' printed promotional materials. This study found that the knowledge of the manufacturers that supermarkets do adjust their margins on particular stock units.

The results indicated that the KVI were an important component in the design of competitive pricing and promotional strategies from a retailing viewpoint. In addition to this, they were seen to have a major influence in explaining unit price variation. It is also apparent that these KVI correspond to brand package sizes, which have the lowest regular unit price and were found to be the ones that were frequently promotionally priced.

The second group of influencing factors to be investigated as a potential cause of unit price variation are those relating to the influence of supplier or manufacturing organisations' pricing strategies and policies in respect to Fast Moving Consumer Goods (FMCG) products. Cost-plus pricing was seen to be the most common form of price strategy (Govindarajan\& Antony, 1983; Gray et al., 1996; Varssnji, 1986. "Variations to this were likely to apply on some products where lower margins could be applied to high turnover products" (Dolan \& Simon, 1996, p18).

Manufacturers predominantly use cost-plus as their method of arriving at a price charged to the supermarkets (Varsanyi 1986),(Gray et.al. (1996). By comparing these two studies it was found that, over a ten-year period manufacturers had not significantly changed their pricing methods. In addition, managers described their knowledge of cost inputs as "relatively good". The research confirmed the previous literature findings, $79 \%$ of managers reported that cost plus pricing was the method most commonly used method. In such a situation the package price charged would reflect its cost and where there was a unit price difference it would be due to cost differences.

Manufacturer or supplier prices are also modified through negotiation (Gabor, 1990, p50; Biscourp, Boutin, \& Verge, 2013) and may lead to a possible reduction in the unit price. Private label products (Goorman, 1981; (Martell, 1986;Gooner, Nadler\&Scott, 2012) were seen to be the highest volume products. The establishment of the size of a branded product that represents the private label size may indicate the size that is most economical to produce, and hence have the lowest unit price.

\section{How does this result fit with hypotheses?}

Two competing ideas were postulated:

1. Supermarkets set prices through channel power and by using simplistic methods (e.g. cost plus price). High turnover products attract lower margins within a supermarket and therefore lower priced, and finally, promotional products within a supermarket have a lower unit price because they are given the goods for lower unit price by suppliers.It is expected that supermarket prices will reflect the purchase cost from suppliers and that supermarket overheads will be applied at a constant rate (cost-plus approach- a predominant form of pricing). Furthermore, particular products will have lower margins applied to them. 
2. Suppliers to supermarkets set prices by recommending prices to maximise profitability and enhance brand value (for the manufacturer). The mechanism for this included: a predominant cost-plus approach for FMCG, higher turnover products within a product range will have a lower margin applied to them by manufacturers or suppliers, list prices of particular products within a range are modified through negotiation between manufacturers or suppliers and the supermarkets to determine the extent of private label production and what is their place relative to the normal product range produced.

While the fact that supermarkets and suppliers will have differing pricing strategies is nothing new, this study explores the different views that suppliers and retailers have of each other with respect to price setting strategies.

1. The manufacturers believe that the supermarket price will reflect the purchase cost from manufacturers or suppliers. This belief can be found in the literature which contended that conventional norms would apply with a channel and margins would be applied at a constant rate as products moved through it (Oxeneldt 1975). If this was the case and manufacturers' Recommended Retail Prices (RRP) were followed then any variation in unit prices would be as a result of manufacturer or supplier actions. When managers representing these manufacturers were interviewed they stated that RRP prices were still issued to the supermarkets. However, the majority of managers believed that they were no longer using RRP's and that the supermarkets were applying their own standard margins and adjusted these on particular products. Based upon this analysis it is concluded that the supermarket retail price may not reflect the purchase cost from manufacturers and that unit price variation could be due to a supermarket's retail action.

2. Suppliers would have an advantage: Any manufacturer or supplier economies will be reflected in lower unit costs at the supermarket level.Large orders were seen as being more cost efficient to produce and should result in lower unit prices (Eckert \&Leftwich, 1988 p631). These economies were classified in with the emphasis being on cost economies and scale economies. The managers of the manufacturing or suppliers firms had previously confirmed that they predominately applied a cost-plus approach to price setting, as such any savings generated by volume production would be passed on to the supermarket retailers.

This study found that theresults support the proposition, that higher turnover products within a product range will have a lower margin applied to them by manufacturers or suppliers.

This study proposed that List prices of particular products within a range are modified through negotiation between manufacturers or suppliers and the supermarkets and of manufacturers to determine the extent of private label production and what is their place relative to the normal product range produced. This study found thatthe proposition that list prices are modified through negotiation was supported.

As a consequence of the research it was possible to develop an integrated model of supermarket pricing behaviour. The model follows two streams, one for standard products, and one for KVI, and how they are applied in practice. This theory has 
application to multi-product organisations where their offering is frequently purchased.

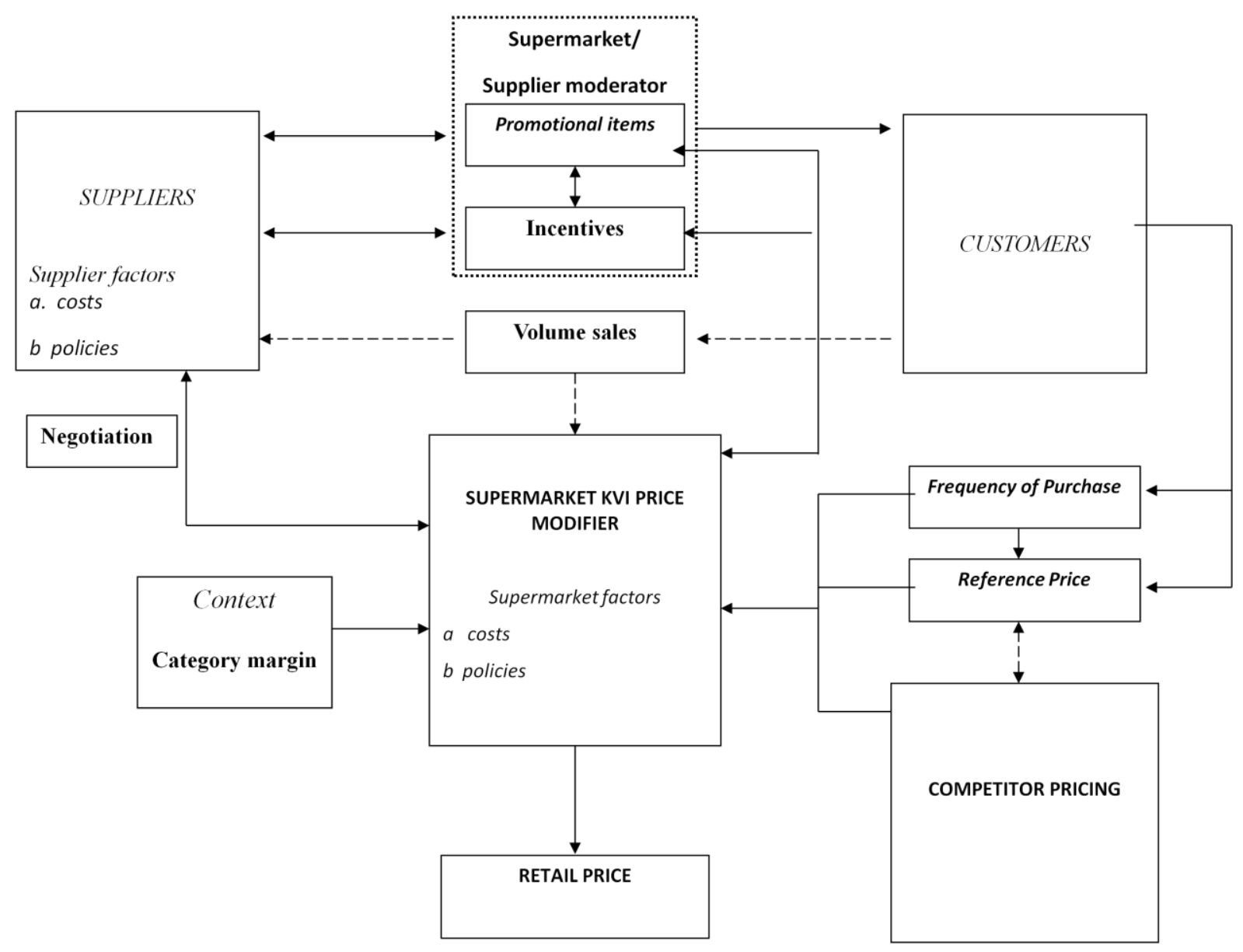

Figure 1: An Integrated Model of Supermarket Pricing Behaviour

Price modifiers were seen by a number of authors as a means of reducing the cost of products (Gabor, 1990, Hirshleifer\& Glazer 1992, Jeuland\&Shugan 1983 and Nagle \& Holden, 1995). The modifiers were seen to be coming from two directions, first from suppliers as encouragement to purchase and second, from the supermarkets in the form of negotiated or contract prices. Both of the supermarket buyers (representing two supermarket groups) interviewed knew that the prices of individual products varied due to prices being negotiated. The managers from the manufacturers or suppliers confirmed that this situation existed. The modifications were based upon manufacturers or suppliers giving discount for bulk purchase, category discount or through supermarkets either negotiating a price or through the supermarkets obtaining contract prices.

According to the managers who represented manufacturers or suppliers the supermarkets adjusted their prices for a variety of reasons. Modifications are then made to them according to turnover rates. When this result is combined with the knowledge that from a manufacturing or supplier perspective they also modify prices in line with turnover and the supermarkets generally have a cost plus approach to price setting then the conclusion that is drawn is that the size with the highest turnover would in all probability have the lowest mark-up in comparison to all other product sizes within a product range. 


\section{Strengths of this study}

Strengths of the study include the in-depth interview technique which allowed for full answers and explanations to be given by the respondents. This meant that answers were not limited to the forced-choice responses that much research uses today. Free response interviews are an advantage because subtleties of opinions can be elucidated, that a forced choice design would not.

All the supermarket chains operating in New Zealand that are represented in the study all had a high degree of unanimity between them on all issues. The supermarkets did have timely cost data on products purchase costs, but all had a problem with cost allocations with regard to non-direct product costings. This lack of specific cost data was one which management in generally was aware of, and was working to address. Prices are set on a cost plus basis for the majority of products. This confirms what the manufacturers had indicated. The basis for the amount of margin added on however does need some explanation.

While the sample size may appear small, it included all the individuals responsible for the pricing decision-making and it also included all of the major supermarket retailers in New Zealand at the time. This study also sought to increase the reliability of the study results by including a third phase to the study. In addition, this study had temporal advantage of being conducted within four months.

Finally, this research may also apply to other similar industries, not just the food industry where a broad product offering can be found and where particular items are purchased frequently by a particular customer.

\section{Conclusions}

This study gives invaluable insight into pricing practices of the supermarket industry, by informing of the power balance that takes place regarding the relationship between suppliers and retailers. While both the retailers and the suppliers each think they have the level of power that enables them to dominate price setting practices, the reality is that in most situations the retailers (supermarkets) retain the balance of power in the distribution channel. The major outcome of interviews with both manufacturers and suppliers was the notion of "Key Value Items" and the role they may play in explaining unit price variance. Analysis of the role and use of these Key Value Items by the supermarket retailers, and their relationship to pricing strategy, and policy, then formed a major part of the final research.

The research identified that for KVI a number of common characteristics in regards to costing and pricing policies applied to both suppliers and supermarkets. Both supermarket customers and supermarkets competitors also influence these items. The research results confirm the proposition the most common pricing method use within the New Zealand Supermarkets is cost plus.

The supermarket industry is relatively uniform in regards to the pricing policies that they use. If they all believe in the application of a particular principal, such as the setting and use of reference prices, then they will all pursue similar courses of action. 
The supermarket industry interviews confirmed that high volume products/sizes might attract a lower margin. If the majority of these products/sizes fall within the above criteria then it is likely that a lower margin would apply in order to attract customers through a policy of low margin/high turnover. This would in turn be reflected in the appearance of a 'quantity surcharge' when various sizes were compared to each other. The high level of agreement between the various lists generated by this research is shown; the unanimity of managers in acknowledging the existence of key value items and their matching unanimity in refusing access to these lists by this researcher, represents compelling evidence for the existence of key value items, and the use of lists of key value items as a key price related marketing tool in the FMCG sector in New Zealand. Based upon this research it can be seen that the key value item products within a supermarket do attract the lowest unit price. This finding is a major factor in the explanation of unit price variance. It is also important from a theoretical viewpoint to understand the usage and application of key value items from both a managerial and consumer viewpoint.

\section{References}

Biscourp, Pierre.,Boutin, Xavier., and Verge, Thibaud (2013) "The Effects of Retail Regulation on Prices: Evidence from the LoiGalland" The Economic Journal,vol123, issue 573, p1279 - 1312, 2013.

Bruce, Annabel (2010) "Making Customers Stick", The Australian Journal of Pharmacy, 91, October, 74-75.

Chun, Dal-Young., Jack M. Cadeaux, (2010) "How supplier category management policy influences category sales performance", Asia Pacific Journal of Marketing and Logistics, Vol. 22 Issue 2, pp.222 - 231.

Draganska, M. Klapper, D. and Villas-Boas, S.B. (2010).A Larger Slice or a Larger Pie?An Empirical Investigation of Bargaining Power in the Distribution Channel. Marketing Science, 29:1 57-74.

Ellickson, Paul B., SanjogMisra (2008) "Supermarket Pricing Strategies" Marketing Science, 27 Issue 5, September-October 2008, pp. 811-828.

Gibson, Richard (1993) "Broad Price Cuts May Not Pay", Wall Street Journal, May 7, B1-B8.

Gooner, Richard A., and Nadler, S Scott (2012) "Abstracting Empirical Generalization from Private Label Brand Research", Journal of Marketing theory and Practice, vol. 20, issue 1, p87-104.

Gray, Brendon, Phil Matheson, BiljanaJuric, Sheelagh Matear, Christo Boshoff and James Henry (1996) Market Orientation, Pricing and Perceived Performance, New Zealand Marketing Management Research Programme, department of Marketing, University of Otago, Dunedin.

Hamilton, Ryan., and Chernev, Alexander (2013) "Low prices are Just the Beginning: Price Image in Retail Management", Journal of Marketing Management, vol 77, No6, 1-20.

Hingley, Martin.,Lindgreen, Adam., and Grant, David B., (2015) "Intermediaries in powerladen retail supply chains: An opportunity to improve buyer-seller relationships and collaboration" Journal of Industrial Marketing Management. May 2015.

Kaufmann P.J., N C Smith, G K Ortmeyer (1994) "Deception in Retailer High-Low Pricing: A "Rule of Reason" Approach", Journal of Marketing Research , 70, 2, 115-138.

Kumar, V., Robeert Leone (1998) "Measuring the Effect of Retail Store Promotion on Brand and Store Substitution", Journal of Marketing Research, 25, May, 178-185.

Lal, Rajiv., Carmen Matutes (1994) "Retail Pricing and Advertising Strategies", Journal of Business, 67, 3, 345-371.

Mulhern, Francis J. , Robert P Leone (1991) "Implicit Price Bundling of Retail Products: A Multiproduct Approach to Maximising Store Profitability", Journal of Marketing, 55, October, 63-76. 
Narasimhan, Chakravarthi (1988) "Competitive Promotional Strategies", Journal of Business, 61, 4, 427- 429.

Nyström, Harry.,Jans Tamsons, Robert Thams (1975) "An Experimental in Price Generalization and Discrimination", Journal of Marketing Research, 12, May, 177-181.

Varssnji, John (1986) Pricing Behaviour of New Zealand companies: a Marketing Managers View, Unpublished honours dissertation, Marketing Department, University of Otago, New Zealand.

Walters, R., Scott McKenzie (1988) "A Structural Equation Analysis of the Impact of Price Promotion on Store Performance", Journal of Marketing Research, 25, February, 51-63 